\title{
In vitro Drug-Drug Interaction Studies of Gliclazide With Levofloxacin By Using HPLC: Guidelines for Co-prescription Drugs
}

Santosh S. Chhajed*, Harshala Chaudhari, Yatish Rajderkar, Akshada Pingle, Sandeep Sonawane, Sanjay Kshirsagar Department of Pharmaceutical Chemistry MET, Institute of Pharmacy, Nashik-422003

\section{Abstract:}

A simple, accurate reversed-phase high-performance liquid chromatography method was developed and validated for simultaneous determination of gliclazide (GLZ) and fluoroquinolone antibacterial levofloxacin (LVO). The method was developed by using a stainless steel analytical column C18 $(250,4.6 \mathrm{~mm}, 5 \mu \mathrm{m})$. The system was operated using mobile phase consisting of methanol and phosphate buffer $(\mathrm{pH} 3.0)$ at a flow rate of $0.8 \mathrm{~mL} \mathrm{~min}{ }^{-1}$ with ultraviolet detection monitored at wavelength $228 \mathrm{~nm}$. The above method was validated using $\mathrm{ICH}$ analytical method validation guidelines. Utilizing HPLC techniques, an assay was intended to determine in vitro effects of levofloxacin on sulphonyl urea an anti-diabetic gliclazide. Obtained results were further verified with UV spectrophotometric method. Availability of gliclazide was reduced in the presence of levofloxacin. This in vitro analyses confirms the co-administartion of gliclazide and levofloxacin and may serve the foundation for designing further in vivo studies.

\section{Experimentals}

In the present investigation, an attempt has been made to develop a sensitive, simple, accurate, rapid and reproducible reverse-phase HPLC method for simultaneous determination of LVO and GLZ, an representative sulphonylurea class of drug followed by its validation, in accordance with the $\mathrm{ICH}$ guidelines.

\section{Optimized Chromatographic Condition}

Isocratic elution with mobile phase methanol: phosphate buffer $\mathrm{pH} 3.0(70: 30)(\mathrm{v} / \mathrm{v})$ was carried out on phenomenex kinetex C18 column $(250 \times 4.6 \mathrm{~mm}, 5 \mu \mathrm{m})$ at flow rate of $0.8 \mathrm{mLmin}^{-1}$ the wavelength was fixed at $228 \mathrm{~nm}$

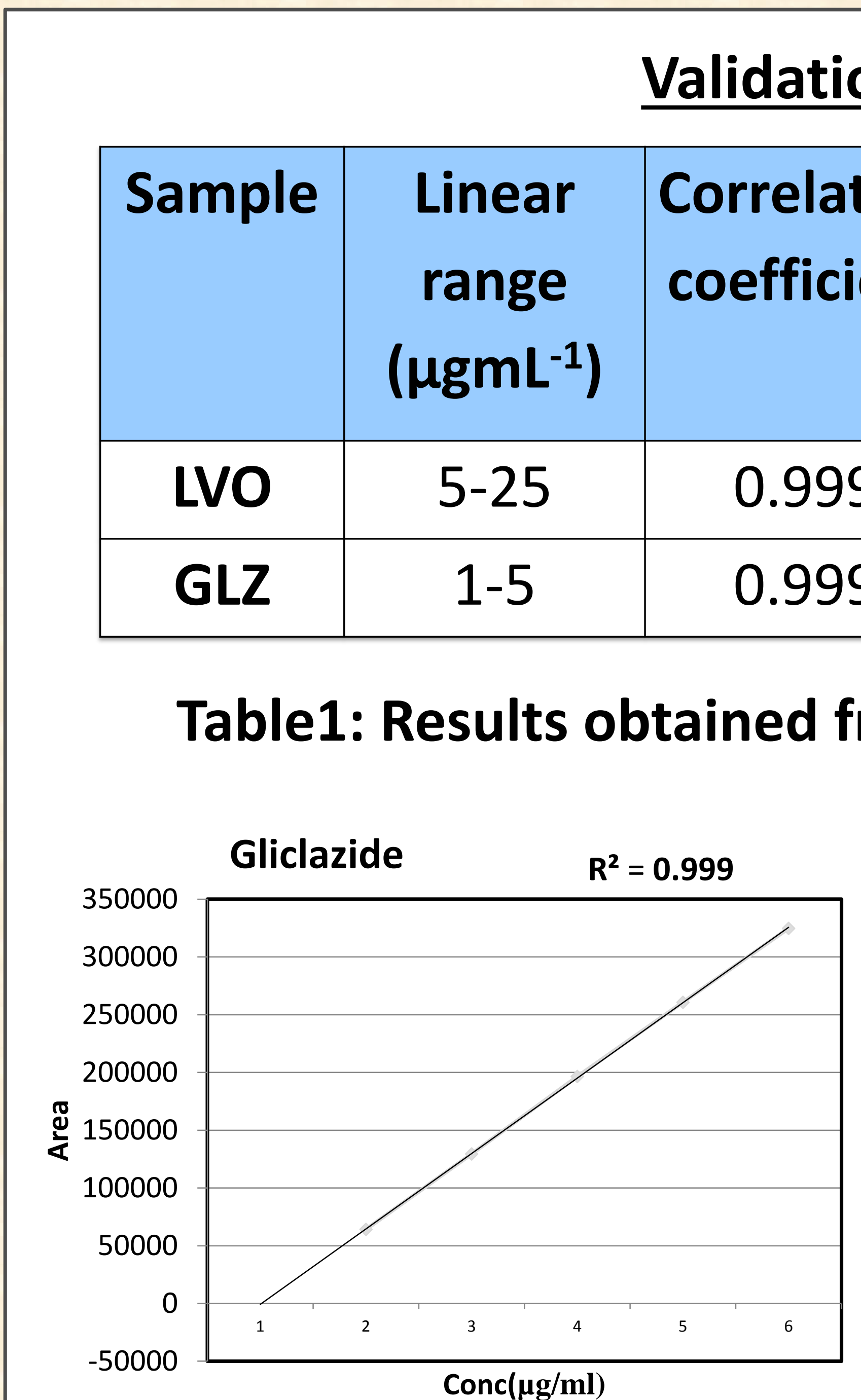

Fig. 1: Linearity Curve Of Levofloxacin

\section{Validation studies}

Correlation LOD

LOQ

\begin{tabular}{|c|c|c|}
\hline 999 & 0.050407 & 0.319787 \\
\hline
\end{tabular}

from linearity, LOD, and LOQ

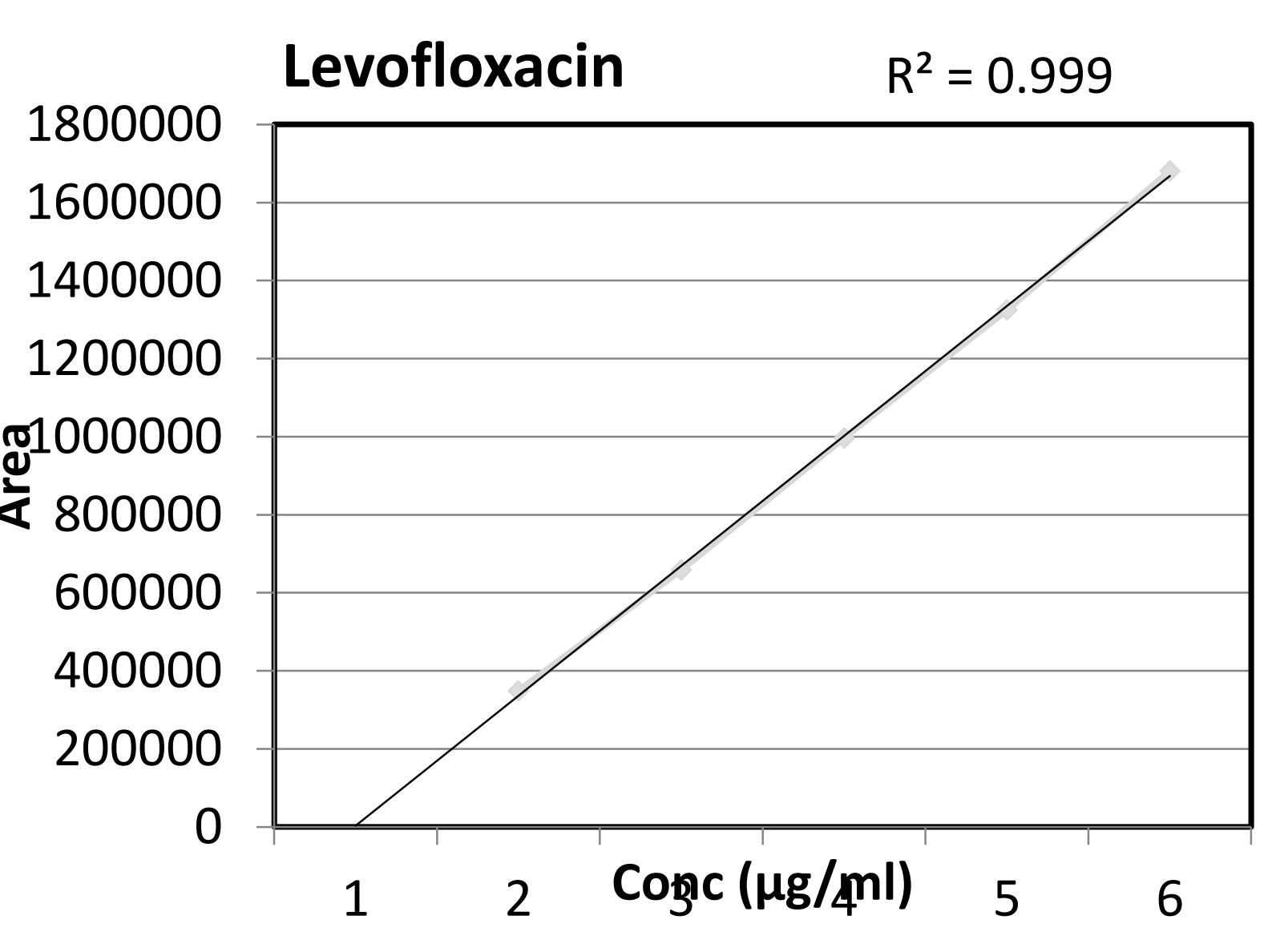

Fig.: 2 Linearity Of Gliclazide

\section{Introduction}

Diabetes mellitus (DM), a major lifestyle disease is undoubtedly the most challenging public health problem of 21st century. Diabetes is a chronic metabolic disease that occurs when the human body is not able to produce enough of the hormone insulin.

Gliclazide (GLZ) is a well-known antidiabetic agent prescribed frequently for treatment of DM. GLZ known to act by its selective binding with sulfonylurea receptors (SUR-1) on the surface of the pancreatic beta-cells which in turn leads to exocytosis of insulin vesicles leading to insulin release.

Levofloxacin (LVO) is an fluoroquinolone class of antimicrobial agent use for the treatment of different infections. LVO is active against both Gram-positive and Gramnegative bacteria. It acts by inhibiting the two type enzymes, namely DNA gyrase and topoisomerase IV ${ }^{1}$

\begin{tabular}{|c|c|c|c|c|c|c|c|c|c|}
\hline \multicolumn{4}{|c|}{ Gliclazide } & \multicolumn{5}{c|}{ Levofloxacin } \\
\hline \multirow{2}{*}{ Injection } & \multicolumn{2}{|c|}{ Intraday } & \multicolumn{2}{|c|}{ Interday } & \multicolumn{3}{|c|}{ Intraday } & \multicolumn{2}{|c|}{ Interday } \\
\cline { 2 - 11 } & Area & $\begin{array}{l}\text { RSD } \\
(\%)\end{array}$ & Area & $\begin{array}{l}\text { RSD } \\
(\%)\end{array}$ & Injection & Area & $\begin{array}{l}\text { RSD } \\
(\%)\end{array}$ & Area & $\begin{array}{l}\text { RSD } \\
(\%)\end{array}$ \\
\hline \multirow{2}{*}{$\mathbf{1}$} & 75040 & & 75964 & & 1 & 357142.7 & & 352537 & \\
\hline $\mathbf{2}$ & 76511 & & 76390.5 & & 2 & 351285 & & 358729 & \\
\hline $\mathbf{3}$ & 76337 & 0.75 & 75626 & 0.40 & 3 & 355478 & 1.32 & 359271 & 1.34 \\
\hline $\mathbf{4}$ & 76578.3 & & 76321 & & 4 & 362371 & & 359271 & \\
\hline $\mathbf{5}$ & 76329.8 & & 76392 & & 5 & 364444.5 & & 358796 & \\
\hline $\mathbf{6}$ & 76231 & & 76193 & & 6 & 359141 & & 367542 & \\
\hline
\end{tabular}

Table 2: Precision parameters of Drugs

\begin{tabular}{|c|c|c|}
\hline Time (mins) & $\begin{array}{l}\text { Gliclazide } \\
\left(\mu \mathrm{gmL}^{-1}\right)\end{array}$ & 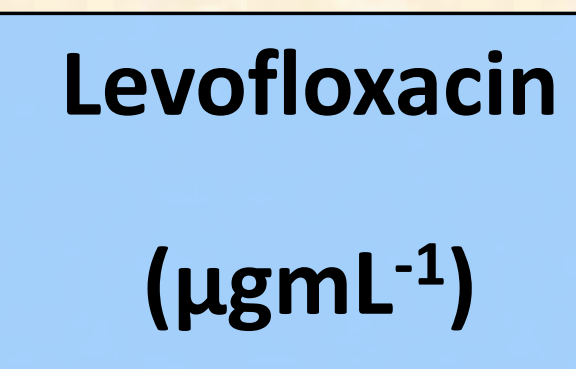 \\
\hline 0 & - & - \\
\hline 15 & 4.75 & 0.48 \\
\hline 30 & 13.47 & 3.49 \\
\hline 45 & 15.84 & 10.63 \\
\hline 60 & 25.33 & 23.64 \\
\hline 75 & 31.6 & 43.10 \\
\hline 90 & 36.77 & 54.23 \\
\hline 105 & 45.47 & 66.14 \\
\hline 120 & 51.50 & 83.49 \\
\hline
\end{tabular}

Table 3: Percent availability of gliclazide after interaction with levofloxacin

\begin{tabular}{|c|c|c|}
\hline Time (mins) & $\begin{array}{c}\text { Gliclazide } \\
\left(\mu \mathrm{gmL}^{-1}\right)\end{array}$ & $\begin{array}{c}\text { Levofloxacin } \\
\left(\mu \mathrm{gmL}^{-1}\right)\end{array}$ \\
\hline $\mathbf{0}$ & - & - \\
\hline $\mathbf{1 5}$ & 8.49 & 0.51 \\
\hline $\mathbf{3 0}$ & 12.42 & 3.09 \\
\hline $\mathbf{4 5}$ & 19.86 & 11.48 \\
\hline $\mathbf{6 0}$ & 26.47 & 25.11 \\
\hline $\mathbf{7 5}$ & 34.44 & 42.50 \\
\hline $\mathbf{9 0}$ & 45.63 & 54.67 \\
\hline $\mathbf{1 0 5}$ & 52.55 & 65.97 \\
\hline $\mathbf{1 2 0}$ & 62.94 & 83.55 \\
\hline
\end{tabular}

Table 4: Percent availability of Gliclazide and Levofloxacin in individua dosage form

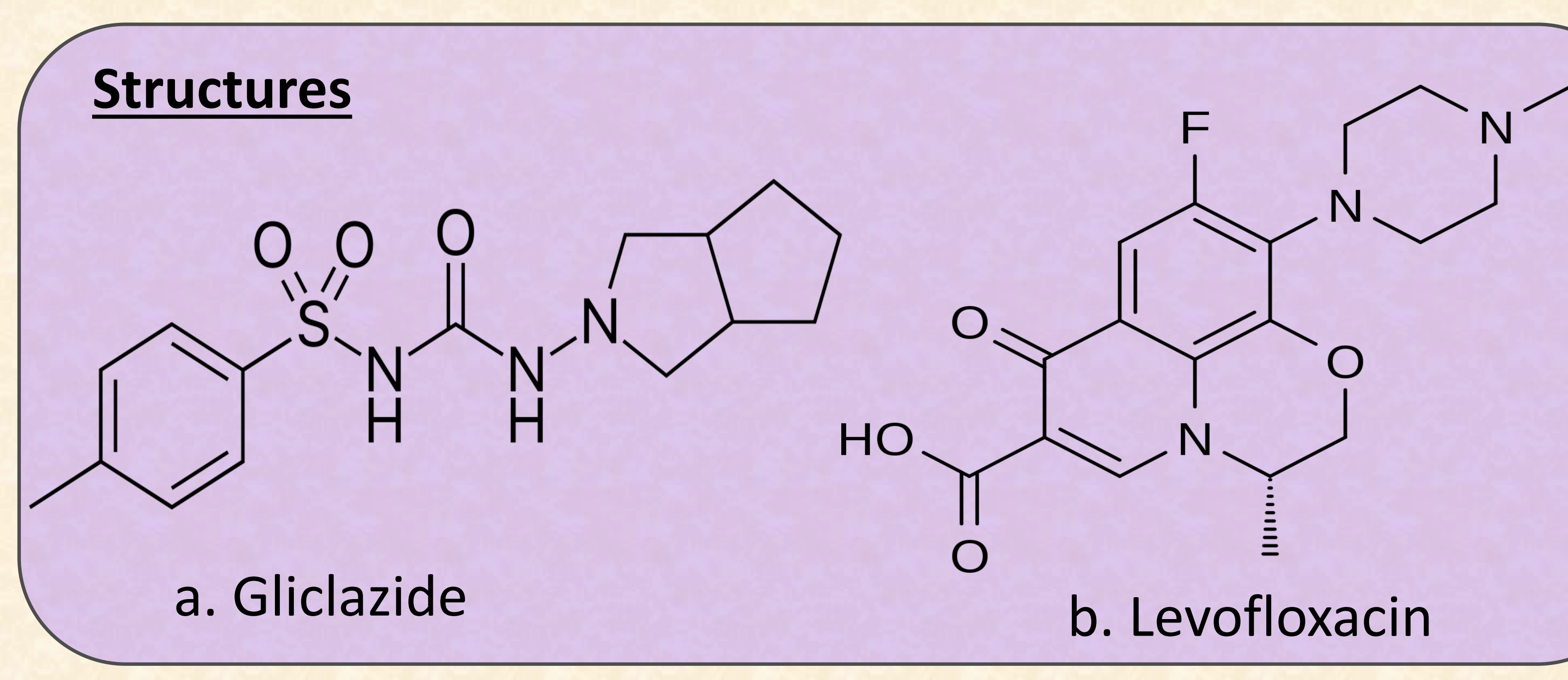

\section{Earlier work: Literature}

$\square$ Drug interaction occurs in between Levofloxacin and sulfonylurea class of anti-diabetic agents which leads to rare fatal side effects.

Hence it is necessary to study absorption interactions occurring between these drugs.

$\square$ To the best of our knowledge, there is no analytical HPLC method reported for simultaneous estimation of these two co-prescription drugs.

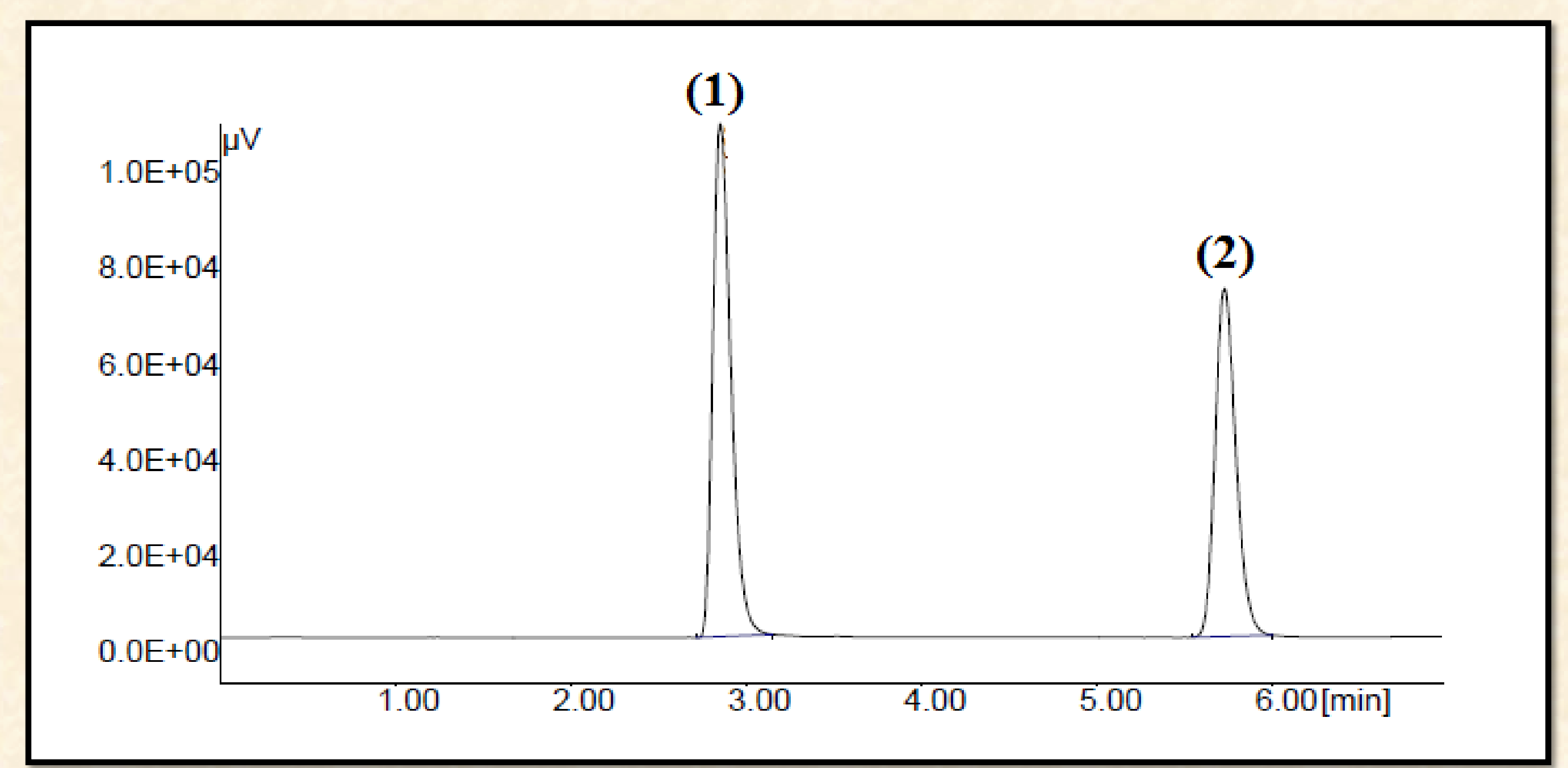

fig: 3 Representative chromatogram of levofloxacin (1) and gliclazide (2)

\section{Results And Discussion}

Simple and reliable HPLC method for simultaneous estimation of drugs GIZ and LVO in the active have been developed for co-prescription drugs.

- It has been observed that absorption gliclazide was decreased significantly that is 0.28 percent when taken along with levofloxacine.

The outcome of the developed HPLC method demonstrates that simultaneous determination of gliclazide and levofloxacin is very useful for pharmaceutical manufacturers, physicians and clinicians.

\section{Conclusion}

From the present study it is concluded that developed method was used to understand interaction of gliclazide on fluoroquinolone antibacterial levofloxacin with significant precision and robustness.

\section{Key References}

Geerlings SE, Hoepelman Al. Immune dysfunction in patients with diabetes mellitus (DM) FEMS Immunol Med Microbiol. 1999;26:25665.

Muller LM, Gorter KJ, Hak E, Goudzwaard WL, Schellevis FG Hoepelman Al, et al. Increased risk of common infections in patients with type 1 and type 2 diabetes mellitus. Clin Infect Dis. 2005:41:281 8.

. Peleg AY, Weerarathna T, McCarthy JS, Davis TM. Common infections diabetes: Pathogenesis, management and relationship to glycaemic control. Diabetes Metab Res Rev. 2007;23:3-13.) 